\title{
Demo de Pnix: la asamblea ateniense en Caballeros de Aristófanes
}

\author{
Julián Gallego \\ Universidad de Buenos Aires/PEFSCEA-CONICET \\ julianalejandrogallego@hotmail.com \\ ORCID iD: https://orcid.org/0000-0002-3394-357X
}

\section{Demos of Pnyx: the Athenian assembly in Aristophanes' Knights}

\begin{abstract}
Se estudia la representación de la asamblea en $\mathrm{Ca}$ balleros de Aristófanes, considerando la coyuntura en que se escenificó y analizando la figura de Demo de Pnix. Se indaga la conexión entre espacios que la obra forja y se postula una dialéctica entre líderes y Demo que enfatiza la autoridad soberana de éste, quien en definitiva los sometía a rendición de cuentas. Se desarrolla finalmente un examen de los sentidos del término dêmos a partir de los debates modernos sobre el vocabulario político, resaltando la existencia de significados en tensión que, al igual que sucede con Demo como personaje cómico, designaban los conflictos que atravesaban al pueblo como cuerpo político.
\end{abstract}

Palabras clave: Atenas; democracia; Aristófanes; asamblea; dêmos.
This paper studies the representation of the assembly in Aristophanes' Knights, considering the circumstances in which it was staged and focusing on the character of Demos of Pnyx. It investigates the connection between spaces that the play molds and it postulates a dialectics between leaders and Demos that emphasizes the sovereign authority of the latter, who ultimately submitted them to accountability. Finally, an examination of the senses of the term dèmos is developed from modern discussions on the political vocabulary, highlighting the existence of meanings in tension that, as with Demos as a comic character, designated the conflicts that went through to the people as the body politic.

Key words: Athens; democracy; Aristophanes; assembly; dēmos.

Cómo citar este artículo / Citation: Gallego, Julián 2019: «Demo de Pnix: la asamblea ateniense en Caballeros de Aristófanes», Emerita 87 (1), pp. 23-46.

\section{Aristófanes y el pensamiento de la politica}

La inferencia de la postura de Aristófanes sobre la democracia ateniense, a partir de sus supuestas críticas o encomios, cualidades atribuidas a los personajes, posiciones fijadas en las parábasis, etc., ha sido un modo de intentar

Copyright: (C) 2019 CSIC. Este es un artículo de acceso abierto distribuido bajo los términos de la licencia de uso y distribución Creative Commons Reconocimiento 4.0 Internacional (CC BY 4.0). 
esclarecer su efectiva toma de partido y determinar así su juicio concreto al respecto $^{1}$. Una escena que ha suscitado este tipo de enfoques es el diálogo entre Demo y el coro en Caballeros (1111-1150), donde ocurriría una mutación en la personalidad de Demo pero a quien de entrada los caballeros describen con rasgos semejantes a los usados hasta ese momento, que mostrarían su estulticia:

Coro: Oh Demo, hermoso es el poder ( $\dot{\alpha} \rho \chi \eta ́ v)$ que tienes, pues todos los

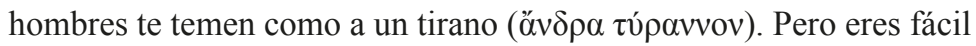

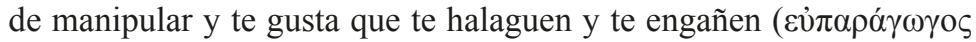

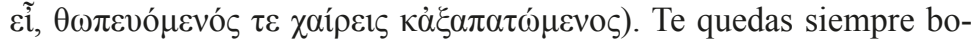

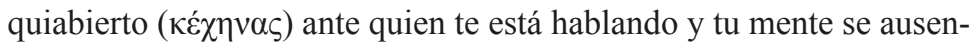
ta aun estando tú presente.

Demo: Donde no está la mente es en vuestras melenas, si creéis que no estoy

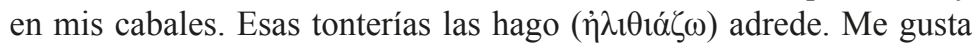
reclamar a gritos la comida, y quiero, por si me roba, criar a un solo

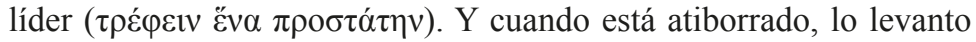

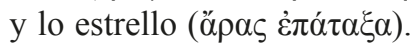

Coro: En tal caso, haces bien, si en esa tu forma de ser hay tan buen seso

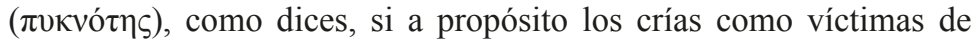

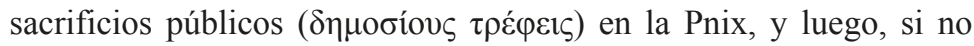
tienes alimento, al que de ellos esté bien cebado, lo sacrificas y te lo almuerzas.

Demo: Miradme, si no les busco las vueltas con pericia a quienes se las dan de listos y creen que me engatusan ( $\dot{\varepsilon} \xi \alpha \pi \alpha \tau u ́ \nu \lambda \varepsilon v v)$. A cada paso los

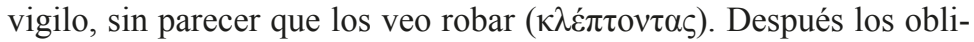

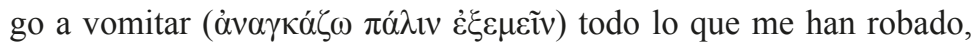

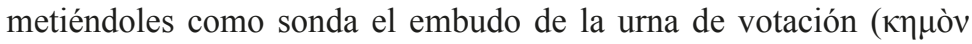
$\kappa \alpha \tau \alpha \mu \eta \lambda \tilde{\omega} v)^{2}$.

Como era de esperar, los estudiosos han dado la merecida atención a este amebeo. Sin anhelo de exhaustividad y haciendo caso omiso de importantes diferencias entre los análisis, cabe identificar una primera línea de interpretación que subraya la insensatez de Demo, sin cambios sustanciales a lo

\footnotetext{
${ }^{1}$ Al respecto, Olson 2010; Gallego 2018.

2 Traducción: Gil 1995, con leves cambios; ediciones consultadas: Sommerstein 1981; Henderson 1998; Wilson 2007.
} 
largo de la obra. Ford 1965 plantea un contraste entre la estupidez de Demo en la primera parte de la comedia, que remitiría a la situación real existente, y la metamorfosis que él debería sufrir mediante un renacimiento intelectual, que quedaría representado por este pasaje. Yunis 1996, pp. 57-58 piensa que para no herir a la audiencia Aristófanes busca equilibrar las críticas previas poniendo en boca de Demo la idea de que no es estúpido y sabe lo que hace. Reinders 2001, pp. 170-178, 189-192 (cf. íd. 1995) colige que el poeta tuvo éxito al atacar al dêmos y caracterizarlo como necio reduciendo al mínimo la posibilidad de recibir cargos judiciales por denigrarlo. Edwards 2010, pp. 322, 326-327 y n. 44 indica que si bien Demo es representado como un amo cuyos sirvientes políticos pueden, metafóricamente, ser tratados como animales a sacrificar y comer en un festival, no obstante, Demo es quien resulta ser esclavo de la kolakeía competitiva de los demagogos al ofrecerse en su aspecto político de asamblea como ámbito para la contienda. Olson 2010, pp. 6667 (cf. íd. 1990) cree que, más allá de lo que expresan estos versos, para Aristófanes el pueblo como colectivo político es tonto y vive guiado por los líderes, que son en verdad quienes ejercen el poder. Tsoumpra 2010, § 2.3-6, señala que en esta escena Demo no sufre transformación alguna respecto de su condición previa y la que muestra después, sino que sigue siendo alguien que depende de sus líderes y no alcanza a ser más sabio que al comienzo.

Otra línea de explicación, también con matices entre las posturas, percibe un sentido positivo en el rol de Demo. Para Brock 1986, pp. 19-26 se trata del momento en que alcanza plena consciencia de su papel, lo cual ha de ser tomado en serio, ya que la solución debe provenir del propio Demo, reformándose a sí mismo, puesto que tiene parte de culpa por la situación vigente. Según MacDowell 1995, pp. 106-107 estos versos muestran que, a pesar de sus puntos débiles y errores, Demo consigue triunfar en la asamblea por su honestidad y sentido común. Slater 2002, pp. $79-80$ y n. 39 destaca que el

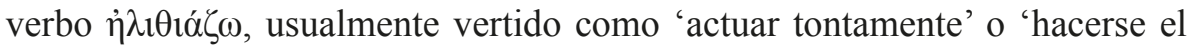
tonto', tiene aquí el sentido de tontería juvenil más que una forma de actuación consciente; pero la política de Demo en sí misma no es tonta sino que parece haber una «teoría política rudimentaria detrás de sus acciones», cuyo límite, no obstante, es que solo actúa sobre los políticos una vez que ya han cometido sus tropelías. Scholtz 2004, pp. 282-283, 289 formula su interpretación en un plano diferente: el interludio lírico hace advenir la stásis como recurso de la intriga cómica haciendo coincidir los intereses de la multitud (Demo) con los de la minoría (los caballeros) para desenmascarar a los de- 
magogos. Para Rosen 2010, pp. 251-253 esta escena interpela a la audiencia para que reexamine la acción previa a partir de mostrar la omnisciencia de Demo, que sabe de antemano lo que sucede con las disputas entre líderes; así, la sátira resulta inocua para aquellos del público que ya conocen la situación. Según Major 2013, pp. 77-79 Aristófanes destaca en estos versos que la única forma de alcanzar la prosperidad es a través de los procesos deliberativos de la democracia, mediante el gobierno y el juicio de Demo, que debe participar y conducir, haciendo valer su parecer y afirmando su saber y liderazgo. En fin, Schere 2015, pp. 41-42 sostiene que Demo representa a un sector amplio y heterogéneo, y de allí sus aparentes inconsistencias, lo cual no es comprendido por los caballeros que lo critican y subestiman.

Este amplio arco de posturas, algunas planteadas en un plano alusivo, otras concebidas de manera más metafórica, nos reconduce a la dificultad indicada: querer hallar cuál fue la verdadera postura política de Aristófanes; pero, por más que la tuviera como cualquier otro ciudadano, no se trata de deducirla para determinar si habla bien o mal del pueblo, o si lo critica pero luego lo disimula, etc. En efecto, más que responder con un sí o con un no a la cuestión de si Aristófanes fue partidario o adversario de la democracia, lo significativo es tratar de comprender los posibles efectos de pensamiento en el momento de la representación teatral que los enunciados pudieron generar acerca del agente político de la democracia. En tal sentido, Lombardini 2012 plantea que en Caballeros existe una reflexión sobre el problema de la autoridad política a partir de la autoridad del discurso y el poeta cómicos, procediendo a una desinvestidura de esta última en el propio desarrollo de la trama. Esto produciría una afinidad entre los rasgos de la autoridad cómica y los de la democrática, que recaía sobre los ciudadanos comunes que participaban en el proceso de decisión de la política, afirmando así la capacidad reflexiva de los integrantes del pueblo. Dicho de otro modo, la comedia aristofánica desarrollaría un pensamiento de la política ateniense en relación con lo que denominaré proceso de subjetivación del agente, esto es, el empoderamiento del dêmos, a partir de la libertad e igualdad de palabra, el debate sobre las disyuntivas, la toma de decisión y la responsabilidad del acto y sus consecuencias. En definitiva, el discurso cómico operaba como recurso de reflexión sobre este proceso de configuración del dêmos como sujeto político.

Esta línea de argumentación se encuadra en el debate acerca de la homología entre la reunión asamblearia y la audiencia teatral (cf. Gallego 2016), y cómo ambos espacios se alimentaban mutuamente. Las reflexiones de Aristó- 
fanes sobre la práctica asamblearia destacan esta conjunción y permiten acceder así a un modo de pensamiento de la política democrática. Rhodes 2004 ha examinado las comedias en las que se representa o se alude a un encuentro asambleario: Acarnienses (1-203), Tesmoforiantes (76-764) y Asambleistas (1-310), enfocándose en el modo en que Aristófanes refleja los aspectos institucionales de la asamblea y enfatiza su soberanía, cuya capacidad no era limitada ni por el Consejo ni por ninguna otra instancia de gobierno; la asamblea era hasta tal punto poderosa que los demagogos solo pudieron convertirse en líderes políticos a partir de ganarse su apoyo. Rhodes 2010 analiza la representación de la asamblea en Caballeros (720-1260), con el fin de enmendar la omisión de su análisis en el estudio previo (donde solo citaba los vv. 624-692 en que se aludía al Consejo). El primer aspecto que resalta es que la convocatoria a celebrar asamblea y decidir se expresa en un lenguaje que recuerda el de los decretos asamblearios. Los discursos de Paflagonio y Morcillero empiezan con imprecaciones que rememoran las que pronunciaban los heraldos al inicio de los encuentros o las plegarias que aparecen en los decretos. Otros aspectos aluden a las prácticas al uso en Atenas, como la prerrogativa que se arroga Paflagonio de ser alimentado en el Pritaneo, honor que se confería por los servicios prestados a la ciudad, como el que recibió Cleón después de Pilos (Eq. 280-281, 719, 766, 1404); o el uso de guijarros para votar en los juicios, que en el siglo $\mathrm{V}$ aportaban los propios ciudadanos, y los embudos que coronaban las urnas de votación para conservar el secreto del sufragio de cada ciudadano. Asimismo, cabe mencionar el hecho de conferir el honor de ocupar la proedría, asiento de privilegio en el teatro, como el que recibió Cleón por el triunfo en Pilos (Eq. 575, 702-704). Ahora bien, en $C a-$ balleros un punto básico es la escenificación del pueblo ateniense en la figura de Demo y la del demagogo Cleón en la de Paflagonio ${ }^{3}$, que Kidd 2014, pp. 55, 69-70, examina como estructuras transparentes de sentido que una vez fijadas abren paso a desmontajes y desestabilizaciones paródicas, el libre juego de la lengua ${ }^{4}$. Detengámonos primero en una de esas estructuras transparentes de sentido antes de considerar los desmontajes y desestabilizaciones.

${ }^{3}$ Se han propuesto otras alusiones, p. ej. Morcillero como sucedáneo de Alcibíades: Vickers 1997, pp. 98-106, que es seguido, con reservas, por Sidwell 2009, pp. 158-160, 164-165. Para críticas a esta visión, Sommerstein 2005, p. 230 = íd. 2009, p. 219; sobre Alcibíades, Gribble 1999, pp. 29-89.

${ }^{4}$ Véase Slater 2002, pp. 68-85, 262-267. 
Las alusiones a la figura de Cleón y la práctica demagógica (Eq. 191-193, 211-219) deben encuadrarse en la Guerra Arquidámica, cuando Atenas estaba sumida en la disputa entre los líderes sucesores de Pericles, según Tucídides (II 65.10), que al no sacarse ventajas y aspirar cada uno a ser el más influyente, empezaron a complacer al pueblo poniendo todos los asuntos en sus manos. La coyuntura en que se representa Caballeros es en la situación posterior al triunfo en la expedición ateniense a Pilos-Esfacteria. Esta victoria sobre los lacedemonios y las repercusiones favorables a Cleón son referidas en varias ocasiones $(E q$. 54-57, 76, 355, 702, 742-743, 844-846, 1005-1006, 1058-1060, 1166-1167, 1172, 1201) $)^{5}$, con la explícita mención del trofeo de los escudos arrebatados a los espartanos, que seguían teniendo las agarraderas (Eq. 843-859) y que Cleón habría dedicado a la diosa políada en el templo de Atenea Nike ${ }^{6}$. Detrás de la imagen de bête noire que las fuentes nos brindan casi unánimemente sobre Cleón es necesario, pues, discernir su acción política concreta, que Lafargue 2013 y Saldutti 2014 han abordado recientemente con perspicacia. Permítasenos ilustrarlo con el debate en una asamblea en el año 425/24 que deriva, precisamente, en el éxito militar en Pilos.

La descripción de Tucídides deja ver el funcionamiento de la asamblea y el quehacer del demagogo ${ }^{7}$. Cleón desacredita a unos informantes sobre lo que sucede en Pilos; pero al ser designado inspector para verificar los hechos, se ve obligado a proponer una expedición; ataca entonces a Nicias señalando que si los estrategos fueran hombres ya habrían concluido la misión y si él mismo estuviera al mando ya lo habría hecho (IV 27.3-5). La multitud se alborota contra Cleón; buscando obtener provecho, Nicias lo desafía a que se haga cargo de la expedición. Cleón se excusa diciendo que él no es el estratego sino Nicias; pero la multitud apoya a éste y pone a aquél en evidencia. A Cleón no le queda más remedio que aceptar el mando (IV 28.1-4). Sin embargo, en estas condiciones va a saber sacar fuerzas de su posición de debilidad: hace que la asamblea vote su propuesta según lo que considera necesario para la misión y elige a Demóstenes, estratego que ya estaba en

5 Ver Th. IV 26-41; Lafargue 2013, pp. 51-70; Saldutti 2014, pp. 137-154. En este marco se entienden las trabas para lograr la paz con Esparta; Ar., Eq. 667-673, 792-796, 805-808, 1388-1395, con Worthington 1987.

${ }^{6}$ Lippman-Scahill-Schultz 2006. Ver Ar., Eq. 1090-1095, 1168-1182; Anderson 1991; 1995, pp. 9-38; Lauriola 2006; Bartoletti 2015.

7 Retomo aquí un análisis desarrollado en Gallego 2003, pp. 140-141. 
Pilos, para que lo acompañe (IV 28.4-29.1; cf. Ar., Eq. 391-394). De esta forma, por dos veces, cuando la opinión de la mayoría estaba por dar un mentís a sus palabras, Cleón capta la predisposición popular e interpreta desde el punto de vista político qué es lo se debe decir: ante la propuesta de enviarlo como inspector, lo cual lo conduciría a confirmar lo dicho por los informantes y quedar como embustero, señala que si los atenienses confían en las noticias entonces hay que enviar la expedición sin perder más tiempo; frente al desafío de Nicias para que actúe como estratego, acepta el mando, pide suficientes tropas, se hace secundar por un general experimentado y logra así en la arena política una victoria que prontamente se confirma con el desarrollo favorable de los hechos en la campaña militar (IV 39.4-40.2) ${ }^{8}$. Este triunfo de Cleón en la asamblea, corroborado por los efectos positivos de la decisión adoptada siguiendo su propuesta, no debe perderse de vista como horizonte de lo que Caballeros refiere sobre el vínculo entre los demagogos y el dêmos, las condiciones para el liderazgo asambleario y la responsabilidad que recaía sobre los oradores al asumir el rol de dirigentes que aconsejaban acerca de la decisión que se debía tomar99.

\section{Demo de Pnix: agente, espacio, asamblea}

Siguiendo a Kidd, pasemos ahora a analizar en Caballeros los desmontajes y desestabilizaciones paródicas. La escena no representa a una asamblea, evocando claramente el funcionamiento de dicha institución, pero la ekklesía se menciona como tal en cuatro ocasiones ( $E q .76,305,746,936)$, o también a partir de la referencia locativa de la colina de Pnix $(165,749,751,1109$, 1137), o a través de las fórmulas pròs tòn dêmon (710), eis tòn dêmon (723) o simplemente tòn dêmon $(714,720)$, mostrando así la concomitancia entre pueblo y asamblea. Cuando Paflagonio le pide a Demo que convoque a una reunión para que pueda decidir, Demo no se deja disuadir por la oposición de Morcillero a que el debate se desarrolle en la Pnix, y reafirma que la asamblea solo puede tener lugar allí (746-751). Desde entonces el intercambio

\footnotetext{
${ }^{8}$ Sobre el debate, Flower 1992; Murari Pires 2003; sobre la expedición militar, Westlake 1974; Babut 1986.

9 Estos problemas, abordados en el fecundo artículo de Finley 1962, han generado gran cantidad de publicaciones, p. ej. Connor 1971; recientemente, Lane 2012; Rhodes 2016; sobre Cleón, Lafargue 2013, pp. 125-148.
} 
entre Paflagonio y Morcillero supone una reunión de la asamblea (763-1263). Es cierto que en este caso no nos hallamos ante una oratoria de asamblea, pues la discusión se da bajo la forma del agón cómico ${ }^{10}$; pero la situación es resuelta por el dêmos reunido en asamblea en la Pnix, que decide a partir del debate entre ambos demagogos a quién tendrá como líder ${ }^{11}$.

¿Quién es Demo en Caballeros? Apenas iniciada la pieza se lo identifica

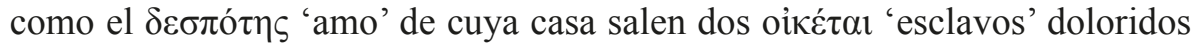
por los golpes recibidos, aparentemente con máscaras de Demóstenes y Nicias $^{12}$, lo cual remite a la idea de que se trata de un amo al que deben servir. El nombre de Demo para este personaje propone un horizonte que atraviesa toda la obra: es el dueño que habita en la casa, al que no solo estos antiguos esclavos sino también los nuevos que pueda incorporar tienen que servir. Su nombre, $\Delta \tilde{\eta} \mu о \varsigma$ Пикvítпs 'Demo de Pnix', se enuncia como habitualmente se designaba a un ateniense, identificando la localidad de procedencia a partir del modelo instaurado por Clístenes, según el cual un ciudadano debía ser registrado mediante la inscripción en su demo de origen fijando así su pertenencia. Esto enfatiza de inmediato que la idiosincrasia de Demo viene dada por el lugar que ocupa en el espacio de reunión de la asamblea y que se trata de un sujeto que se configura en dicho ámbito, a la vez que se identifica con el mismo. Según el primer criado:

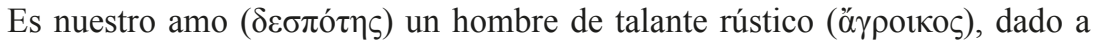
comer habas y propenso a la cólera: Demo de Pnix, un vejete cascarrabias,

${ }^{10}$ De todos modos, Major 2013, pp. 64-82, destaca el factor deliberativo en esta comedia; cf. Long 1972.

${ }^{11}$ Sobre el debate entre Paflagonio y Morcillero, Whitman 1964, pp. 80-103; MacDowell 1995, pp. 97-103; De Luca 2005, pp. 41-67; Schere 2012, 2013a, pp. 113-118. Telò 2014 estudia este debate a la luz de la rivalidad entre Aristófanes y Cratino; cf. Sidwell 2009, pp. 56-86. Sobre la crítica al demagogo y al dêmos, Ford 1965; según Tsoumpra 2010, los ataques se dirigen más al pueblo que a Cleón y la demagogia. Edmunds 1987a, 1987b plantea

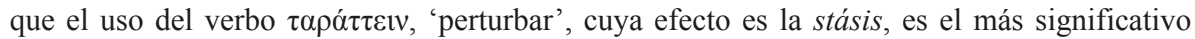
para describir la política de Cleón, como si fuera una tormenta en el mar que perturba la nave del estado y la pone en peligro; ver Cannatà 1995; McGlew 1996 = íd. 2002, pp. 86-111; Bastin-Hammou 2013; Burns 2014.

12 Argumento, I 49, 58-60 = A 3.1, 8-9 (Jones-Wilson 1969); cf. Dover 1959. Para Sommerstein 1980, 1981, pp. 144-145, se trata de ambos políticos; Schere 2013b, 2015, pp. 38-39, adopta esta misma postura. Según Henderson 1998, p. 222, n. 2, 2003b, Aristófanes pone en escena a dos personajes sin alusiones precisas. 


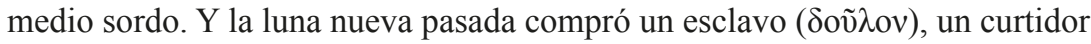
de pieles paflagonio, marrullero redomado y grandísimo calumniador. El susodicho pielero-paflagonio se caló la forma de ser del viejo, se echó a los pies del amo y se puso a hacerle carantoñas, a halagarle, a adularle y engañarle

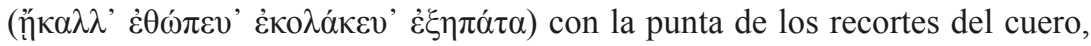
hablándole así: «Demo, toma un baño no más hayas juzgado un solo pleito,

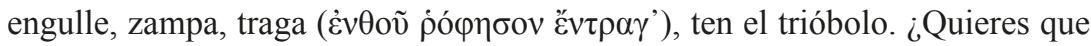

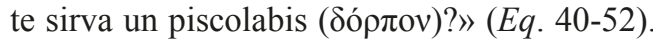

La imagen no es diferente a la que aparece en boca de Morcillero justo después de que Demo determinase que la sesión de la asamblea solo podría celebrarse en la Pnix: «En casa (oî́kot), el viejo es el más inteligente de los hombres, pero, cuando toma asiento en esa roca, se queda boquiabierto

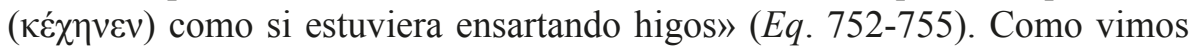
al inicio (1111-1120), si bien parece haber una transformación en la caracterización que se hace de Demo a medida que va transcurriendo el diálogo con los caballeros, la impresión acerca de él que éstos exponen de entrada presenta rasgos muy semejantes a los que le ha asignado el primer criado en su descripción al comienzo de la obra: a pesar de ser temido como un tirano, Demo es fácil de manipular, adular y engañar y se queda boquiabierto

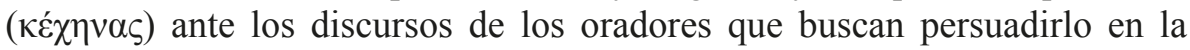
asamblea.

Este cuadro de situación es similar a la visión de Aristóteles (Pol. 1292a

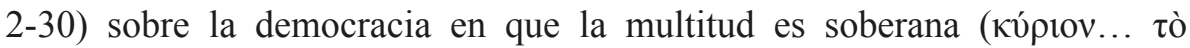
$\pi \lambda \tilde{\eta} \theta$ os) pero no la ley. Su argumento resalta que este empoderamiento de la

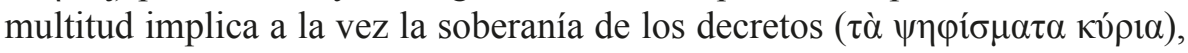
gracias al papel que desempeñan los demagogos; así, el pueblo deviene un

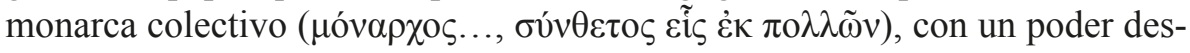

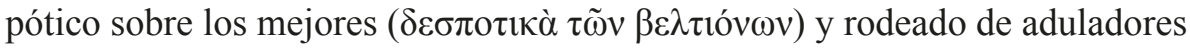
(кó $\lambda \alpha \kappa \varepsilon \varsigma$ ), que para llegar a ser sus líderes presentan todos los asuntos ante

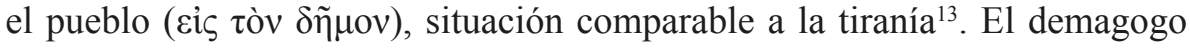
llega a ser el amo (кúpıov) de la opinión del pueblo, porque la multitud le obedece $(\pi \varepsilon i \theta \varepsilon \tau \alpha \imath)$. Ya vimos esta misma cuestión en el pasaje de Tucídides (II 65.10) sobre la lucha por el liderazgo suscitada tras la muerte de Pericles,

13 Sobre la articulación entre soberanía popular, tiranía y control de los magistrados, ver Landauer 2012, 2014, Hoekstra 2016; Lane 2016; cf. los trabajos reunidos en Morgan (ed.) 2003. 
cuando los contendientes implementaron la adulación al pueblo para que decidiera todo.

La visión de Aristóteles parece un certero compendio de los aspectos que se destacan en Caballeros de Aristófanes: la soberanía del dêmos que decide todo por medio de decretos en asamblea, eis tòn dêmon, según se lee en am-

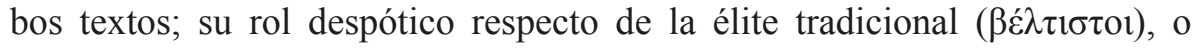
como despótes de los esclavos (¿Demóstenes y Nicias?) que salen de la casa de Demo y remitirían a dicha élite; la adulación de los líderes hacia el dêmos como modo de vinculación entre ambos; su preferencia por los demagogos, como ocurre con Paflagonio y Morcillero, que guían al dêmos y se hacen dueños de su opinión, quien a su vez parece dejarse engañar; la comparación con la tiranía planteada por ambos textos, o también el pueblo como monarca, al igual que lo indica el corifeo en Caballeros $(1330,1333)$ cuando dice que el dêmos es el monarca de la Hélade.

Pero Demo de Pnix no solo es lo que de él se piensa, sino también cómo actúa, empezando por los lugares que va ocupando y cómo se apropia de cada uno de ellos a medida que los habita. Varios análisis han subrayado estos aspectos señalando el problema de la actuación pública de Demo a partir del hecho de haber sido definido en relación con el ámbito doméstico. Según Zumbrunnen 2004, pp. 670-672 = íd. 2012, pp. 93-96, la inteligencia de Demo en su hogar implica a la pluralidad de los ciudadanos en privado, de lo cual no se deduce que su actuación política colectiva en la asamblea sea igualmente inteligente. Para De Luca 2005, pp. 3-13, 46-47, en la medida en que Demo es consciente de su propio poder, la interfaz entre lo privado y lo público encarnada en él se resuelve siempre en función de su propio interés, es decir, conforme a sus necesidades; pero estas dimensiones espaciales no son compartimentos estancos sino que, de acuerdo con la hipótesis de De Luca, la trama de Caballeros hace colapsar lo privado y lo público, ya que se trata de una democracia absoluta que genera el colapso absoluto de ambas esferas. En su estudio del espacio aristofánico, Papathanasopoulou 2013, pp. 116-159, siguiendo la visión de De Luca, analiza cómo se retratan en Caballeros los mundos cívico y doméstico a partir de los usos y cambios en el espacio escénico que complican la alegoría: del oîkos sobre la escena al bouleutérion entre bastidores, nuevamente al oîkos, luego a la Pnix y otra vez al oîkos; la deliberada borradura de las fronteras espaciales ayuda a que los espectadores visualicen a Demo a la vez como individuo y como grupo, enfatizando así tanto el rol de los ciudadanos individuales cuanto el del pueblo como totalidad. 
Esto se percibe bien en Caballeros (722-751). Demo se halla en su casa, que en los argumentos se identifica con la ciudad (A 1.3, 1.6) ${ }^{14}$. En un momento de la acalorada discusión entre Paflagonio y Morcillero, ambos invocan a Demo a gritos; el primero indica que se debe ir a la asamblea; el segundo consiente con esto. Los dos solicitan que salga de su casa. Cuando finalmente lo hace, Demo les reclama que se larguen de su puerta, lo cual, por cierto, no ocurrirá. Como ya vimos, Paflagonio le pide que celebre de inmediato una asamblea para que juzgue y decida por sí mismo, poniendo en Demo la capacidad de convocarla. Morcillero acuerda con que la decisión le corresponde a Demo, pero no quiere que la contienda se celebre en la Pnix sino que desea concretarla en el ágora que es su lugar de crianza, como veremos a continuación y como él mismo indica cuando revela su nombre:

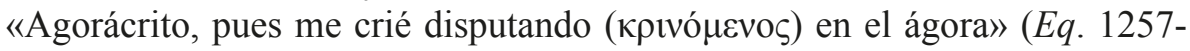
1258); y tal vez también porque percibe que Paflagonio se ha hecho fuerte en la Pnix gracias al vínculo que ha desarrollado con Demo. De todos modos, éste responde que en ningún otro lugar que no sea la Pnix puede realizarse la reunión de la asamblea. Esto permite pensar en la existencia de tres espacios

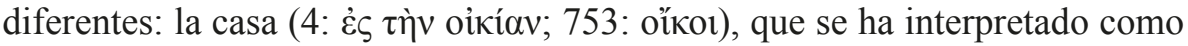
la ciudad pero que aparece estrictamente como el recinto doméstico de Demo, lo cual podría remitir a la idea de la pólis como un gran ốkos ${ }^{15}$; la Pnix, como lugar en que Demo adquiere su dimensión política concreta, en la medida en que la asamblea es el ámbito soberano de decisión de todos los asuntos de gobierno. He hablado de tres espacios; en efecto, ¿cuál es ese sitio en que se hallan Paflagonio, Morcillero y Demo cuando éste franquea la puerta de su casa, en el que Morcillero pretende resolver el debate sin pasar por la Pnix? Hay un juego entre el adentro y el afuera, una suerte de política de la casa y política de la ciudad ${ }^{16}$, cuya politización ocurre en el caso de Demo por el hecho mismo de tratarse de un sujeto que decide, un agente que pone en

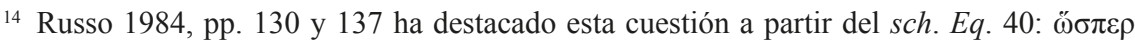

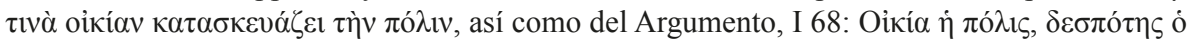

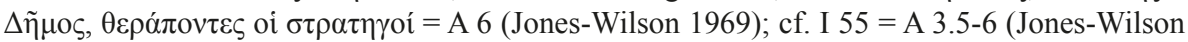

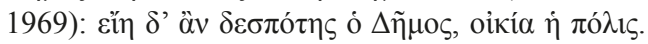

${ }^{15}$ Como se plantea en Ar., Eq. 673-675. Wilkins 2000, pp. 11-12 indica la existencia de una negociación cómica entre espacio cívico y doméstico, en que el primero es metaforizado por el segundo; cf. Gallego 2009, pp. 57-60.

${ }^{16}$ Hutchinson 2011 analiza en el corpus aristofánico las asociaciones y oposiciones entre el hogar y la ciudad. 
claro que para poder hacerlo debe ocupar el espacio de la asamblea en la Pnix. Pero existe a la vez un juego entre la parte y el todo, en una suerte de sinécdoque en que la parte que es la casa designa metonímicamente al todo que es la ciudad, dialéctica entre el todo y la parte que, como veremos al final, resulta precisamente constitutiva de la propia definición de dêmos.

Todo esto no excluye que, junto con la oikía y la Pnix, otro espacio aparezca también con potencia, reforzando la publicidad de la palabra y la acción políticas inherentes al propio hecho de que Demo es el personaje en torno al cual gira la trama. Se trata del ágora, término que en forma sustantiva o adjetiva recorre Caballeros $^{17}$, que es uno de los epítetos que reciben Hermes y Zeus $(297,410,500)$, espacio en el que se halla presente Morcillero, puesto que es su lugar de crianza a partir de su condición de vendedor de morcillas (1257-1258; cf. 293, 636), y donde lo hallan los criados de Demo, desde el cual supuestamente se elevará a la posición de líder «del ágora, los puertos y la Pnix, sojuzgando al Consejo y echando a los estrategos, encarcelando, encadenando y putañeando en el Pritaneo» (147, 164-167). No se prescinde

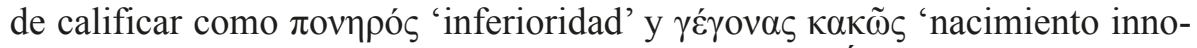
ble' esta procedencia del ágora mercantil $(181,218)$. Área de mercado $(677$, $1009,1245,1373)$ y también de edificios políticos, como el bouleutérion donde se reúne el Consejo representado en Caballeros (624-682), el ágora es claramente un espacio público, que en muchas ciudades continúa siendo el lugar de las reuniones de la comunidad para la toma de decisiones y para el espectáculo teatral ${ }^{18}$. Pero, como ha sugerido Loraux 1999, pp. 28-44, 120137 , por un doble movimiento, en Atenas la asamblea y el teatro se desplazan hacia la Pnix y al pie de la acrópolis, respectivamente. Los enunciados cómicos evocan la separación de los tres espacios, pero a la vez la escena deviene el ámbito de una nueva fusión. Esta intersección entraña la distinción de un espacio respecto de otro pero también su superposición. Así, la casa de Demo, el ágora y la Pnix se enlazan entre sí y, metateatralmente, con el espacio del teatro de Dioniso en el que la comedia se representa. Demo va

${ }^{17}$ Ver Russo 1984, pp. 137-139, sobre los vínculos entre el ágora y la Pnix; cf. Wilkins 2000, pp. 174-201.

18 Sobre la aplicación de la noción de espacio público o esfera pública a la Atenas democrática, Gottesman 2014, passim, a partir de la perspectiva de Habermas. Para otros abordajes de la Grecia antigua y la Atenas democrática utilizando la idea de esfera o espacio público: Azoulay 2011; Lombardini 2013; Jaulin 2014; Landauer 2016. 
ocupando cada instancia, que son sus partes, respecto de las cuales él encarna la totalidad. De la interioridad doméstica de Demo dentro de su casa a su exteriorización pública en el ágora y la Pnix, lo que se manifiesta es la soberanía de la política democrática a través del proceso de convocatoria, desempeño y decisión final de la asamblea.

Debido a este modo de operar de la asamblea en la Pnix, los líderes devienen esclavos en la casa/ciudad de Demo: los dos esclavos antiguos, el nuevo esclavo Paflagonio y Morcillero son otras tantas figuras cuya permanencia como dirigentes políticos apoyados y votados por el dêmos solo puede ocurrir en virtud de su soberanía. No importa que los esclavos o los caballeros, que parecen ser jóvenes de la aristocracia ${ }^{19}$, acusen a Paflagonio y Morcillero, los nuevos políticos estudiados por Connor 1971, de engañar, adular o robarle a Demo, puesto que éste es quien decide el liderazgo. Volviendo a la escena con la que iniciamos este artículo, esto es precisamente lo que se dice en Caballeros (1121-1150): Demo es quien encumbra a un líder

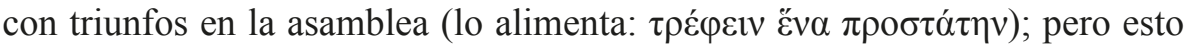
es algo enteramente contingente y está siempre sometido al escrutinio popular, que llegado el caso le quita todo el apoyo y lo castiga (ö $\tau \alpha \nu \tilde{\hat{n}} \pi \lambda \dot{\varepsilon} \omega \varsigma$,

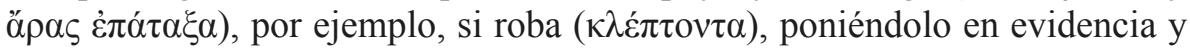
decidiendo acerca de su conducta en la asamblea (lo alimenta como víctima

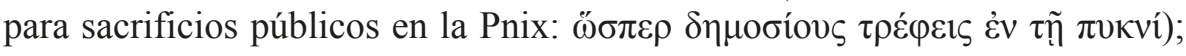
quien engaña ( $\dot{\varepsilon} \xi \alpha \pi \alpha \tau \hat{\lambda} \lambda \lambda \varepsilon ı v)$ al pueblo termina finalmente por rendir cuentas

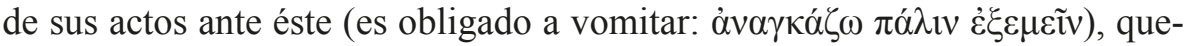
dando así sometido al veredicto de las votaciones democráticas (usando como

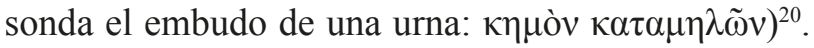

A partir de los aspectos analizados con respecto a los vínculos entre líderes y pueblo, un factor que descuella es la cuestión del engaño, que no puede resolverse de modo unilateral afirmando que los oradores engañan a Demo o viceversa. En efecto, como sugiere Hesk 2000, pp. 289-291, Caballeros de Aristófanes invita a la audiencia, de la cual Demo es una personificación

19 Sidwell 2000 sugiere la existencia de dos semicoros, uno de jóvenes caballeros y otro de viejos jurados vestidos de caballeros, solo distinguibles a partir de una doble entrada, puesto que luego actuarían en conjunto.

${ }^{20}$ Compton-Engle 2015, pp. 45-48, interpreta que este pasaje forma parte de un conjunto de imágenes que recorren la comedia y configuran un cuerpo «impolítico» asociando los pares gula-estómago y boca-ano. 
cómica, a reflexionar sobre los inciertos límites y poderes de su soberanía y su propia autoridad para manipular como marca tanto de la máxima soberanía cuanto de una peligrosa ilusión. En este sentido, los modos de habitar el espacio político permiten destacar que, con respecto a Demo, el demagogo se comporta adorándolo y engañándolo, mientras que Demo es un amo que juega al esclavo, hasta el momento en que decide mostrar su poder soberano reponiéndose en el lugar de $\mathrm{amo}^{21}$. Si es posible invocar la dialéctica del amo y el esclavo, que el propio lenguaje aristofánico pone de relieve, es porque las posiciones activa y pasiva de los personajes no son irreversibles, que es la dificultad manifiesta de las interpretaciones sesgadas que concluyen, como ya hemos visto en Aristóteles (Pol. 1292a 26-27), que el demagogo se convierte en amo de la opinión del pueblo, porque la multitud le obedece. En Caballeros, como expusimos, los líderes son caracterizados de entrada como doûloi de Demo que aparece en posición de despótes; pero en la medida en que los demagogos son capaces de halagar y adular a Demo como a un tirano y al mismo tiempo engatusarlo y embaucarlo con su retórica persuasiva para que haga lo que ellos le proponen, el amo se hace esclavo de sus esclavos. Al decidir sobre si los líderes continúan o no, sometiéndolos a escrutinio y juzgándolos, Demo retorna al lugar de amo de sus esclavos, que quedan sometidos a su autoridad soberana. Aunque parece tener una actitud pasiva, Demo finalmente obliga a los líderes a que rindan cuentas de sus actos, no teniendo él mismo que hacer una rendición de cuentas de los suyos porque es anypeúthynos. Como se revela al final de la obra en boca de Morcillero:

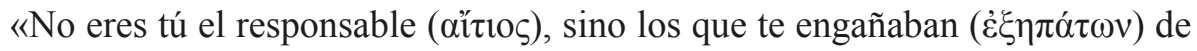
esa forma» (Eq. 1356-1357).

\section{El dêmos y la ekklesía en Atenas}

Sin duda, una ratificación del poder del pueblo se colige del hecho de que su actuación en la asamblea no quedaba comprendida en la rendición de cuentas ( $\varepsilon \dot{\theta} \theta \dot{v} v \alpha$ ): los magistrados eran regularmente sometidos a este procedimiento pero no la asamblea, que al ser soberana no tenía encima de ella ninguna

${ }^{21}$ Sobre la adulación de los demagogos y el carácter tiránico del poder del pueblo en Caballeros, Scholtz 2004, pp. 274-279; Edwards 2010, pp. 319-330; Markovits 2012, pp. 116122; en general, Henderson 2003a. 
autoridad de control. Así, la responsabilidad quedaba circunscripta a la propia asamblea $^{22}$. Según el autor conocido como el Viejo Oligarca, el pueblo solo

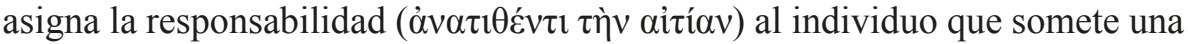
propuesta a votación cuando las consecuencias de lo resuelto por el pueblo son negativas, y acusa ( $\alpha i \tau i \tilde{\alpha} \tau \alpha)$ al promotor de la decisión de haber actuado contra él para destruirlo; pero cuando son positivas el pueblo se atribuye a sí mismo la responsabilidad (aìíav) ([X.], Ath. II 17). En Tucídides (III 43.4), Diódoto revela que, al hacer su proposición, el orador se convierte en el único responsable (i் $\pi \varepsilon v 0 v v o \varsigma$ ), mientras que el público no tiene que rendir

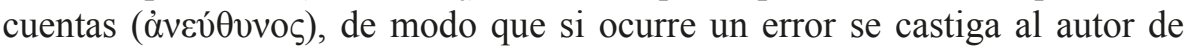
la iniciativa ${ }^{23}$. A partir de esto se ha llegado a la conclusión de que el pueblo era irresponsable ${ }^{24}$, pero cabe en verdad otra interpretación. Los oradores conocían las reglas y debían construir su liderazgo siguiendo los procedimientos vigentes; al hacer una propuesta sabían la responsabilidad que asumían en caso de que fuera votada. La asamblea se preservaba a sí misma como espacio político sometiendo el proceso de decisión a la prueba del resultado y habilitando la eventual enmienda de lo actuado a partir de identificar al autor de la moción, cuyo nombre se inscribía junto con la resolución votada en la asamblea. Pero esto no supone que se diera un lugar concluyente al individuo, pues la fórmula usada tiene básicamente un carácter genérico: o

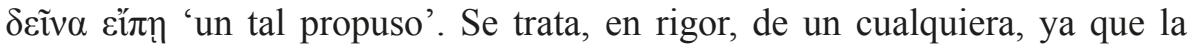
proposición quedaba supeditada a la decisión colectiva de la asamblea. El nombre del impulsor de la iniciativa indica la carga de responsabilidad que el dêmos hacía recaer sobre quien actuaba como orador y ofrecía su palabra a la comunidad ${ }^{25}$.

Si el dêmos era la ekklesía y si ésta era la reunión del cuerpo político que decidía por sí mismo, la responsabilidad puesta sobre el individuo que formulaba una moción actuaba como modo de reforzar la práctica en acto de la soberanía: en la indistinción de la asamblea, quien tomase la palabra debía promover una proposición con resultados positivos para no vulnerar la confianza del

${ }^{22}$ Retomo aquí argumentos planteados en Gallego 2003, pp. 111, 119-120.

${ }^{23}$ Cf. Th. VIII 1.1; And. II 27.

${ }^{24}$ Sobre la «irresponsabilidad» del dêmos y el control de los magistrados, Gil $1970=$ íd. 2009, pp. 57-90; Lévy 1976, pp. 29-47; Elster 1999; últimamente, Landauer 2012, 2014; Lane 2016.

${ }_{25}$ Sickinger 2002 sintetiza el conjunto de cuestiones implicadas en el proceso legislativo. 
pueblo en sí mismo como cuerpo político. Pero si esta convicción se quebraba, entonces, la identificación del autor de la medida adoptada no apuntaba a su individualización en el seno de la asamblea sino a su sanción a posteriori como promotor de un pensamiento perjudicial para los intereses de la comunidad. Más que el carácter irresponsable del dêmos, en realidad, lo que pone de manifiesto la forma de imputar la responsabilidad al autor de una iniciativa es que, así como los magistrados quedaban sometidos a la euthýna, así también en la asamblea se imponía sobre los líderes el procedimiento de la rendición de cuentas.

Un asunto básico que subyace en la cuestión de la responsabilidad del dêmos es el sentido de este vocablo. Para empezar a discernir los aspectos de este problema, es útil una reflexión de Finley 1973, p. 64, que alegaba que en una democracia directa como la de Atenas los ciudadanos no trazaban una línea divisoria tajante entre pueblo llano y élite gubernamental. No obstante, en griego antiguo había diferentes vocablos para decir lo que hoy se entiende por «pueblo

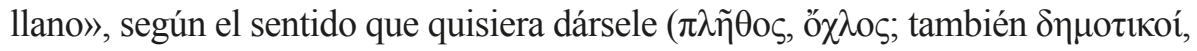

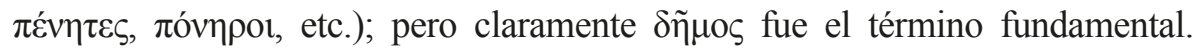
Como también indicaba Finley 1983, pp. 1-2, en este caso el problema radica en la polisemia de la noción, que remitía tanto al cuerpo de ciudadanos como un todo cuanto al pueblo común, los muchos, los pobres; los escritores griegos jugaban libremente con este vocablo echando mano a un sentido u otro, y muchos de ellos operaban sobre esta ambigüedad para criticar a la democracia.

Según Hansen 1978 = íd. 1983, pp. 139-160, dêmos tenía cuatro sentidos: en el plano político-institucional se equiparaba con la ekklesía y se refería al pueblo reunido en asamblea; en una acepción más amplia denotaba a todos los atenienses o, lo que sería lo mismo, al estado ateniense; en su alcance constitucional era sinónimo de demokratía; desde el punto de vista social su uso connotaba a la gente común, el pueblo llano de Finley. Pero el problema de los diferentes sentidos de dêmos no parece agotarse en esta enumeración, por muy abarcadora que se revele, pues si se presta atención existen contradicciones entre las diferentes acepciones.

La perspectiva de Hansen ha dado lugar a una controversia conceptual que gira en torno a la equiparación del dêmos con la ekklesía pero no con los dikastéria, en un sentido estrictamente político e institucional ${ }^{26}$. Ostwald

${ }^{26}$ Para breves alusiones, Rhodes 1981, pp. 317-318, 545; Sinclair 1988, pp. 70-71, 79; cf. Hansen 1985, 1989a. 
1986, pp. 34-35 n. 131 señala que si bien dêmos se asociaba frecuentemente con la asamblea y rara vez con los dikastéria, ello no significa que éstos no deban considerarse como representativos del pueblo como un todo. Ober 1989a, pp. 147-149, 1989b = íd. 1996, pp. 107-122, hace hincapié en un asunto realmente opinable: la idea de representación aplicada por Hansen, proponiendo en su reemplazo la noción de sinécdoque, una parte que refiere simbólicamente al todo. De esta manera, tanto la asamblea como los tribunales serían partes del cuerpo cívico y ambas instituciones aludirían al dêmos como totalidad. Para Hansen 1989b = íd. 1989c, pp. 213-218, la idea de representación solo puede ser aplicada a los dikastéria, ya que sus poderes se derivaban del dêmos ateniense -concebido como el estado-, pero no a la ekklesía que era el dêmos en su sentido institucional.

Recientemente, Blanshard 2004 ha coincidido con Hansen, y piensa que los tribunales dependían del dêmos como conjunto y estaban en una posición subordinada respecto de éste, lo cual entrañaba la existencia de una brecha entre comunidad y jurado, en parte reflejada en la riqueza de las discusiones recientes. Anderson 2009, pp. 11-17 dice que la separación entre ekklesía y dikastéria se daba solo en términos de responsabilidad, ya que los poderes de ambos cuerpos eran manifestaciones de una autoridad única, unitaria y suprema, la persona ficta del dêmos. Así, la relación entre éste y las instituciones no se definiría como una sinécdoque sino como una dependencia mutua. La escisión entre la personalidad unitaria del dêmos y las personas «reales» que lo encarnaban en la vida pública es lo que se percibe en el carácter estatal y autónomo del aparato de ejercicio del poder. Hansen 2010 responde a las críticas, revisa los problemas involucrados en su explicación y reafirma que el dêmos se equiparaba con la ekklesía con el significado de pueblo en asamblea. El autor parece abandonar, además, la idea de representación aplicada

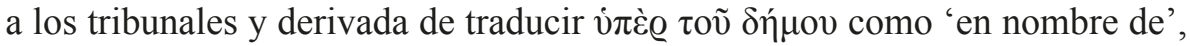
aceptando que la traducción correcta es 'en beneficio de/a favor de'; pero esto no cambia el núcleo de su argumento: la ekklesía no era representativa del dêmos sino que era el propio dêmos actuando como cuerpo de gobierno (Hansen 1987, pp. 96-97, 104).

Se puede colegir que esta ambigüedad, incluso este equívoco, alrededor del vocablo dêmos atestigua la dimensión política del asunto, pues en este contexto resulta claro que la política pasa a ser un atributo del pueblo. Ciertamente, tras el nombre dêmos circula una indistinción entre el conjunto de los ciudadanos y las clases subalternas, así como entre el acto plebiscitario 
de la asamblea y la ley instituida por la constitución de un gobierno, ya que designa tanto a la comunidad entera como a lo que conforma la parte popular, tanto a la reunión asamblearia concreta como al andamiaje institucional de una organización que se considera como un estado, que en la Atenas democrática se nutría de las decisiones asamblearias. Por cierto, estas definiciones de dêmos no son externas a la situación política ateniense, dadas por un observador que la trasciende y la contempla desde afuera, sino que son inmanentes a un mismo plano e inherentes a las condiciones de la política. Siendo así, el equívoco del que hablamos no implica una falta de claridad conceptual sino la instancia misma de un conflicto irresoluble dentro del cuerpo político ateniense, hecho que adquiere expresión en las prácticas de reunirse en el espacio concreto de la asamblea para debatir y tomar decisiones en común.

\section{A modo de conclusión}

Caballeros de Aristófanes representa bajo la máscara y la figura espacialmente situada de Demo de Pnix a un personaje que habilita, dentro de los límites de la escenificación, una serie de dualidades: entre el espacio político y el espacio doméstico, entre la totalidad de la pólis y la particularidad del ốkos, entre la exterioridad de la Pnix y la interioridad de la casa. La yuxtaposición de entramados y la tensión entre los mismos quedan sintetizadas en la figura de Demo, cuya casa es la propia pólis y cuya política en la Pnix afecta al conjunto de sus partes, y vienen a poner de relieve que, al igual que el dêmos, este personaje cómico es un conjunto en conflicto consigo mismo; por eso puede aparecer como tonto que deviene sabio, como amo que juega al esclavo, como viejo que rejuvenece, como anypeúthynos que impone la euthýna. Demo de Pnix es un conjunto, un colectivo, que se identifica con un lugar que es una colina, un sitio geográfico, pero sobre todo un espacio político que el pueblo habita apropiándoselo mediante la práctica de reunirse en asamblea. Un colectivo, un espacio, una práctica: un colectivo político que solo se configura como tal al reunirse para habitar un sitio estipulado, que solo deviene un espacio político por el hecho mismo de dicha reunión, ambos términos, colectivo y espacio, constituidos como tales en virtud de una práctica política sintetizada bajo el nombre de asamblea. Estos tres términos, colectivo, espacio y práctica, que Demo de Pnix viene a condensar en su configuración como personaje cómico, evocan en su solidaridad intrínseca una dimensión que se halla en exceso con respecto a la simple identificación con 
una institución del sistema de gobierno, poniendo de relieve un pensamiento en interioridad de las condiciones de posibilidad de la política ateniense asentada en la soberanía del pueblo.

\section{BiBLIOGRAFÍA}

Anderson, C. A. 1989: «Themistocles and Cleon in Aristophanes' Knights, 763ff», AJPh 110, pp. 10-16.

Anderson, C. A. 1991: «The Dream-Oracles of Athena, Knights 1090-95», TAPhA 121, pp. 149-155.

Anderson, C. A. 1995: Athena's Epithets. Their Structural Significance in the Plays of Aristophanes, Stuttgart.

Anderson, G. 2009: «The Personality of the Greek State», JHS 129, pp. 1-21.

Azoulay, V. 2011: «L'Espace public et la cité grecque: d'un malentendu structurel à une clarification conceptuelle», en Boucheron, P. y Offenstadt, N. (eds.), L'espace public au Moyen Âge. Débats autour de Jürgen Habermas, París, pp. 63-76.

Babut, D. 1986: «L'épisode de Pylos-Sphactérie chez Thucydide: l'agencement du récit et les intentions de l'historien», $R P h$ 60, pp. 59-79.

Bartoletti, T. J. 2015: «Oráculos burlados y enigmas cómicos en Caballeros de Aristófanes», Emerita 83 (1), pp. 23-45.

Bastin-Hammou, M. 2013: «L'orateur et le poète comique: réflexions sur Aristophane et Cléon», en Vial, H. y Favreau-Linder, A.-M. (eds.), Poètes et orateurs dans l'Antiquité. Mises en scène réciproques, Clermont-Ferrand, pp. 57-71.

Blanshard, A. J. 2004: «What Counts as the Demos? Some Notes on the Relationship between the Jury and "the People" in Classical Athens", Phoenix 58, pp. 28-48.

Brock, R. W. 1986: «The Double Plot in Aristophanes’ Knights», GRBS 27, pp. 15-27.

Burns, T. W. 2014: «Anger in Thucydides and Aristophanes. The Case of Cleon», en Mhire, J. J. y Frost, B.-P. (eds.), The Political Theory of Aristophanes. Explorations in Poetic Wisdom, Albany, pp. 229-258.

Cannatà, F. 1995: «La resa scenica del Paflagone nei Cavalieri di Aristofane», MD 35, pp. 117-133.

Compton-Engle, G. 2015: Costume in the Comedies of Aristophanes, Cambridge.

Connor, W. R. 1971: The New Politicians of Fifth-Century Athens, Princeton.

De Luca, K. M. 2005: Aristophanes' Male and Female Revolutions. A Reading of Aristophanes' Knights and Assemblywomen, Lanham.

Dover, K. J. 1959: «Aristophanes, Knights 11-20», CR 9, pp. 196-199.

Edmunds, L. 1987a: Cleon, Knights, and Aristophanes' Politics, Lanham.

Edmunds, L. 1987b: "The Aristophanic Cleon's "Disturbance" of Athens», AJPh 108, pp. 233-263. 
Edwards, A. T. 2010: «Tyrants and Flatterers: Kolakeia in Aristophanes' Knights and Wasps», en Mitsis, P. y Tsagalis, C. (eds.), Allusion, Authority, and Truth. Critical Perspectives on Greek Poetic and Rhetorical Praxis, Berlín, pp. 303-338.

Elster, J. 1999: «Accountability in Athenian Politics», en Przeworski, A., Stokes, S. C. y Manin, B. (eds.), Democracy, Accountability, and Representation, Cambridge, pp. 253-278.

Finley, M. I. 1962: «Athenian Demagogues», $P \& P$ 21, pp. 3-24.

Finley, M. I. 1973: Democracy, Ancient and Modern, New Brunswick.

Finley, M. I. 1983: Politics in the Ancient World, Cambridge.

Flower, H. I. 1992: «Thucydides and the Pylos Debate (4.27-29)», Historia 41, pp. $40-57$.

Ford, Jr., G. B. 1965: «The Knights as a Source of Aristophanes' Attitude toward the Demagogue and the Demos», Athenaeum 43, pp. 106-110.

Gallego, J. 2003: La democracia en tiempos de tragedia. Asamblea ateniense y subjetividad política, Buenos Aires.

Gallego, J. 2009: El campesinado en la Grecia antigua. Una historia de la igualdad, Buenos Aires.

Gallego, J. 2016: «La asamblea, el teatro y el pensamiento de la decisión en la democracia ateniense», Nova Tellus 33/2, pp. 13-54.

Gallego, J. 2018: «La asamblea cómica de Aristófanes y la política democrática ateniense», Phoînix 24/2, pp. 55-74.

Gil, L. 1970: «La irresponsabilidad del dêmos», Emerita 38, pp. 351-373.

Gil, L. 1995: Aristofanes, 1. Acarnienses. Caballeros (trad.), Madrid.

Gil, L. 2009: Sobre la democracia ateniense, Madrid.

Gottesman, A. 2014: Politics and the Street in Democratic Athens, Cambridge.

Gribble, D. 1999: Alcibiades and Athens. A Study in Literary Presentation, Oxford.

Hansen, M. H. 1978: «Demos, Ecclesia and Dicasterion in Classical Athens», GRBS 19, pp. 127-146.

Hansen, M. H. 1983: The Athenian Ecclesia. A Collection of Articles 1976-83, Copenhague.

Hansen, M. H. 1985: «The History of the Athenian Constitution», CPh 80, pp. 51-66.

Hansen, M. H. 1987: The Athenian Assembly in the Age of Demosthenes, Oxford.

Hansen, M. H. 1989a: «Athenian Democracy», CR 39, pp. 69-76.

Hansen, M. H. 1989b: «Demos, Ekklesia and Dikasterion: A Reply to M. Ostwald and J. Ober», C\&M 40, pp. 101-106.

Hansen, M. H. 1989c: The Athenian Ecclesia II. A Collection of Articles 1983-89, Copenhague.

Hansen, M. H. 2010: «The Concepts of Demos, Ekklesia, and Dikasterion in Classical Athens», GRBS 50, pp. 499-536. 
Henderson, J. 1998: Aristophanes, 1. Acharnians. Knights (ed., trad.), Cambridge MA, pp. 219-405.

Henderson, J. 2003a: «Demos, Demagogue, Tyrant in Attic Old Comedy», en Morgan, K. A. (ed.), Popular Tyranny. Sovereignty and its Discontents in Ancient Greece, Austin, pp. 155-179.

Henderson, J. 2003b: «When an Identity Was Expected: The Slaves in Aristophanes' Knights», en Bakewell, G. W. y Sickinger, J. P. (eds.), Gestures. Essays in Ancient History, Literature, and Philosophy Presented to Alan L. Boegehold, Oxford, pp. 63-73.

Hesk, J. P. 2000: Deception and Democracy in Classical Athens, Cambridge.

Hoekstra, K. 2016: «Athenian Democracy and Popular Tyranny», en Bourke, R. y Skinner, Q. (eds.), Popular Sovereignty in Historical Perspective, Cambridge, pp. $15-51$.

Hutchinson, G. O. 2011: «House Politics and City Politics in Aristophanes», $C Q$ 61, pp. 48-70.

Jaulin, A. 2014: «L'espace public dans l'Athènes classique», Philonsorbonne 8, pp. 155-165.

Jones, D. M. y Wilson, N. G. 1969: Prolegomena de comoedia. Scholia in Acharnenses, Equites, Nubes, 2 (ed.), Groninga.

Kidd, S. E. 2014: Nonsense and Meaning in Ancient Greek Comedy, Cambridge.

Lafargue, P. 2013: Cléon. Le guerrier d'Athéna, Burdeos.

Landauer, M. 2012: «Parrhesia and the Demos Tyrannos: Frank Speech, Flattery and Accountability in Democratic Athens», HPTh 33, pp. 185-208.

Landauer, M. 2014: «The Idiōtēs and the Tyrant: Two Faces of Unaccountability in Democratic Athens», Political Theory 42, pp. 139-166.

Landauer, M. 2016: «Democratic Theory and the Athenian Public Sphere», Polis: Journal for Ancient Greek Political Thought 33, pp. 31-51.

Lane, M. 2012: «The Origins of the Statesman-Demagogue Distinction in and after Ancient Athens», JHI 73, pp. 179-200.

Lane, M. 2016: «Popular Sovereignty as Control of Office-Holders: Aristotle on Greek Democracy», en Bourke, R. y Skinner, Q. (eds.), Popular Sovereignty in Historical Perspective, Cambridge, pp. 52-72.

Lauriola, R. 2006: «Athena and the Paphlagonian in Aristophanes' Knights: Reconsidering Equites 1090-5, 1172-81», Mnemosyne 59, pp. 75-94.

Lévy, E. 1976: Athènes devant la défait de 404. Histoire d'une crise idéologique, París.

Lippman, M., Scahill, D. y Schultz, P. 2006: «Knights 843-59, the Nike Temple Bastion and Cleon's Shields from Pylos», AJA 110, pp. 551-563.

Lombardini, J. 2012: «Comic Authority in Aristophanes' Knights», Polis: Journal for Ancient Greek Political Thought 29, pp. 130-149. 
Lombardini, J. 2013: «Isonomia and the Public Sphere in Democratic Athens», HPTh 34, pp. 393-420.

Long, T. 1972: «Persuasion and the Aristophanic Agon», TAPhA 103, pp. 285-299.

Loraux, N. 1999: La voix endeuillée. Essai sur la tragédie grecque, París.

MacDowell, D. M. 1995: Aristophanes and Athens. An Introduction to the Plays, Oxford.

Major, W. E. 2013: The Court of Comedy. Aristophanes, Rhetoric, and Democracy in Fifth-Century Athens, Columbus.

Markovits, E. 2012: «As if We Were Codgers: Flattery, Parrhēsia and Old Man Demos in Aristophanes' Knights», Polis: Journal for Ancient Greek Political Thought 29, pp. 108-129.

McGlew, J. F. 1996: “"Everybody Wants to Make a Speech”: Cleon and Aristophanes on Politics and Fantasy», Arethusa 29, pp. 339-361.

McGlew, J. F. 2002: Citizens on Stage. Comedy and Political Culture in the Athenian Democracy, Ann Arbor.

Morgan, K. A. (ed.) 2003: Popular Tyranny. Sovereignty and its Discontents in Ancient Greece, Austin.

Murari Pires, F. 2003: «Thucydide et l'assemblée sur Pylos (IV.26-28): rhétorique de la méthode, figure de l'autorité et détours de la mémoire», $A H B$ 17, pp. 127-148.

Ober, J. 1989a: Mass and Elite in Democratic Athens. Rhetoric, Ideology and the Power of the People, Princeton.

Ober, J. 1989b: «The Nature of Athenian Democracy», CPh 84, pp. 322-334.

Ober, J. 1996: The Athenian Revolution. Essays on Ancient Greek Democracy and Political Theory, Princeton.

Olson, S. D. 1990: «The New Demos of Aristophanes' Knights», Eranos 88, pp. 60-63.

Olson, S. D. 2010: «Comedy, Politics, and Society», en Dobrov, G. W. (ed.), Brill's Companion to the Study of Greek Comedy, Leiden, pp. 35-69.

Ostwald, M. 1986: From Popular Sovereignty to the Sovereignty of Law. Law, Society, and Politics in Fifth-Century Athens, Berkeley.

Papathanasopoulou, E. 2013: Space in Aristophanes. Portraying the Civic and Domestic Worlds in Acharnians, Knights and Wasps (Ph. D. Diss.), New York, Columbia University Academic Commons $<$ https://academiccommons.columbia. edu/catalog/ac:166609> (06/05/2017).

Reinders, P. 1995: «Der Demos in den Rittern des Aristophanes am Beispiel des Amoibaions in den Vv. 1111-1150», en Zimmermann, B. (ed.), Griechischrömische Komödie und Tragödie, Stuttgart, pp. 1-20.

Reinders, P. 2001: Demos Pyknites. Untersuchungen zur Darstellung des Demos in der Alten Komödie, Stuttgart.

Rhodes, P. J. 1981: A Commentary on the Aristotelian Athenaion Politeia, Oxford. 
Rhodes, P. J. 2004: «Aristophanes and the Athenian Assembly», en Cairns, D. L. y Knox, R. A. (eds.), Law, Rhetoric, and Comedy in Classical Athens. Essays in Honour of Douglas M. MacDowell, Swansea, pp. 223-237.

Rhodes, P. J. 2010: «The "Assembly" at the End of Aristophanes' Knights», en Harris, E. M., Leão, D. F. y Rhodes, P. J. (eds.), Law and Drama in Ancient Greece, Londres, pp. 158-168.

Rhodes, P. J. 2016: «Demagogues and Demos in Athens», Polis: Journal for Ancient Greek Political Thought 33, pp. 243-264

Rosen, R. M. 2010: «Aristophanes», en Dobrov, G. W. (ed.), Brill's Companion to the Study of Greek Comedy, Leiden, pp. 227-278.

Russo, C. F. 1984: Aristofane, autore di teatro [1962], 2a ed. Florencia.

Saldutti, V. 2014: Cleone, un politico ateniese, Bari.

Schere, M. J. 2012: «El tópico del burlador-burlado en los Caballeros de Aristófanes», Nova Tellus 30/1, pp. 19-41.

Schere, M. J. 2013a: «El êthos discursivo de los antagonistas aristofánicos en las comedias Caballeros y Avispas», $C F C(G)$ 23, pp. 111-124.

Schere, M. J. 2013b: «La función argumentativa del personaje de Demóstenes en la comedia Caballeros de Aristófanes», Circe de Clásicos y Modernos 17, pp. 67-84.

Schere, M. J. 2015: «Las críticas contra la aristocracia en la comedia temprana de Aristófanes», Habis 46, pp. 33-48.

Scholtz, A. 2004: «Friends, Lovers, Flatterers: Demophilic Courtship in Aristophanes' Knights», TAPhA 134, pp. 263-293.

Sickinger, J. 2002: «Literacy, Orality, and Legislative Procedure in Classical Athens», en Worthington, I. y Foley, J. (eds.), Epea and Grammata. Oral and Written Communication in Ancient Greece, Leiden, pp. 147-169.

Sidwell, K. 2000: «The Parodos of Aristophanes' Knights», en Hardwick, L., Easterling, P., Ireland, S., Lowe, N. y Macintosh, F. (eds.), Theatre: Ancient and Modern, Milton Keynes, pp. 45-52.

Sidwell, K. 2009: Aristophanes the Democrat. The Politics of Satirical Comedy during the Peloponnesian War, Cambridge.

Sinclair, R. K. 1988: Democracy and Participation in Athens, Cambridge.

Slater, N. W. 2002: Spectator Politics. Metatheatre and Performance in Aristophanes, Filadelfia.

Sommerstein, A. H. 1980: «Notes on Aristophanes’ Knights», CQ 30, pp. 46-56.

Sommerstein, A. H. 1981: The Comedies of Aristophanes, 2. Knights (ed., trad., com.), Warminster.

Sommerstein, A. H. 2005: «An Alternative Democracy and an Alternative to Democracy in Aristophanic Comedy», en Bultrighini, U. (ed.), Democrazia e antidemocrazia nel mondo greco. Atti del Convegno Internazionale di Studi (Chieti, 9-11 aprile 2003), Alejandría, pp. 195-207, 229-233. 
Sommerstein, A. H. 2009: Talking about Laughter and Other Studies in Greek Comedy, Oxford.

Telò, M. 2014: «Aristophanes vs Typhon: Co(s)mic Rivalry, Voice and Temporality in Knights», Ramus 43, pp. 25-44.

Tsoumpra, N. 2010: "Who Is to Blame? Political Leaders and Demos in Aristophanes' Knights», The Athens Dialogues E-Journal <http://athensdialogues.chs.harvard. edu/cgi-bin/WebObjects/Athensdialogues.woa/wa/dist?dis=100> (06/05/2017).

Vickers, M. J. 1997: Pericles on Stage. Political Comedy in Aristophanes' Early Plays, Austin.

Westlake, H. D. 1974: «The Naval Battle at Pylos and its Consequences», CQ 24, pp. 211-226.

Whitman, C. H. 1964: Aristophanes and the Comic Hero, Cambridge MA.

Wilkins, J. 2000: The Boastful Chef. The Discourse of Food in Ancient Greek Comedy, Oxford.

Wilson, N. G. 2007: Aristophanis Fabulae, 1. Acharnenses. Equites. Nubes. Vespae. Pax. Aves (ed., notas), Oxford, pp. 61-128.

Worthington, I. 1987: «Aristophanes' Knights and the Abortive Peace Proposals of 425 B.C.», $A C 56$, pp. 56-67.

Yunis, H. 1996: Taming Democracy. Models of Political Rhetoric in Classical Athens, Ithaca.

Zumbrunnen, J. 2004: «Elite Domination and the Clever Citizen: Aristophanes' Acharnians and Knights», Political Theory 32, pp. 656-677.

Zumbrunnen, J. 2012: Aristophanic Comedy and the Challenge of Democratic Citizenship, Rochester.

Fecha de recepción de la primera versión del artículo: 05/03/2018

Fecha de aceptación: 09/04/2018

Fecha de recepción de la versión definitiva: 18/04/2018 